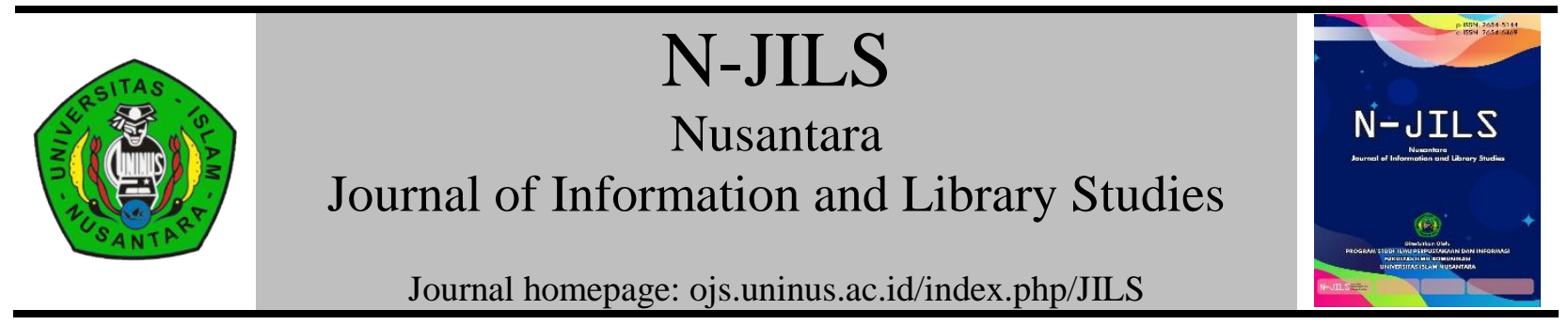

\title{
Inovasi Perpustakaan Melalui Pemanfaatan Teknologi Augmented Reality Dan Virtual Reality di Era Generasi Z
}

\section{Library Innovation Through Augmented Reality and virtual Reality Technology In The Z Generation}

\author{
Dwi Ridho Aulianto* ${ }^{1}$ \\ ${ }^{1}$ Universitas Padjadjaran \\ e-mail: *11wi18009@mail.unpad.ac.id,
}

\begin{tabular}{ll}
\hline ARTICLE INFO & ABSTRACT \\
\cline { 2 - 3 } Article history & This study aims to determine the benefits of \\
Received [May,2020] & Augmented Reality and Virtual Reality technology \\
Accepted [June,2020] & applied to libraries in the Z generation era. The \\
Available Online [June,2020] & research method used study of literature by collecting \\
& several reference as sources that are relevant to the \\
& study material and and interviews with several \\
& generation Z informants. The results of the study \\
& found that the implementation of Augmented Reality \\
& technology can be used to create and read the \\
& Interactive Opac Brochure with AR; Utilization of \\
& Library Collection Display; Utilization for Searching \\
& Library Collections in Shelves through AR; Utilization \\
& for Interactive Learning Media for Users. While the \\
implementation of Virtual Reality technology can be \\
used for tours or library tours; Library Services; \\
Information Literacy and Online Catalog.
\end{tabular}

Keywords: augmented reality; virtual reality; library 
Kata kunci: augmented reality; virtual reality; perpustakaan

\begin{abstract}
ABSTRAK
Penelitian ini bertujuan untuk mengetahui manfaat teknologi Augmented Reality dan Virtual Reality yang diterapkan pada perpustakaan di era generasi $\mathrm{Z}$. Metode penelitian yang digunakan adalah studi litaratur dengan mencari sumber-sumber referensi yang relevan dengan bahan kajian dan wawancara terhadap beberapa generasi Z. Hasil penelitian didapatkan bahwa implementasi teknologi Augmented Reality dapat digunakan untuk membuat dan membaca brosur opac interaktif dengan Augmented Reality; pemanfaatan display koleksi perpustakaan; pemanfaatan untuk penelusuran koleksi perpustakaan di rak melalui Augmented Reality; pemanfaatan untuk media pembelajaran interaktif bagi pemustaka. Sedangkan implementasi teknologi Virtual Reality dapat digunakan untuk wisata atau tur perpustakaan; layanan perpustakaan; literasi informasi dan katalog online.
\end{abstract}

(C) 2020 NJILS. All rights reserved.

\section{A. PENDahuluan}

Perkembangan teknologi informasi yang begitu pesat berdampak pada perubahan perilaku masyarakat dalam melakukan segala aktifitasnya, kegiatan yang awalnya dilakukan secara manual telah beralih kedalam bentuk elektronik, digital atau virtual. Bidang perpustakaan termasuk yang terkena dampak dari pengaruh kemajuan teknologi. Kemajuan teknologi menjadi tantangan bagi perpustakaan untuk tetap eksis dalam memberikan pelayanan pada masyarakat terutama pada era generasi $\mathrm{Z}$ dimana teknologi merupakan sesuatu yang tak terhindarkan. Perpustakaan harus mampu memanfaatkan perkembangan teknologi sebagai pendukung dalam layanan perpustakaan sehingga kebutuhan informasi dan pengetahuan para pemustaka generasi $\mathrm{Z}$ dapat terpenuhi. Seharusnya perpustakaan menjadi sumber informasi dan pusat pembelajaran bagi masyarakat dari berbagai lintas generasi. Namun masih terdapat pemustaka yang merasa kesulitan dan belum bisa menemukan buku yang diinginkan walaupun sudah tersedia fasilitas katalog online (OPAC - Online Public Access Catalog). Hal ini disebabkan karena kurangnya pengetahuan para pemustaka tentang lokasi-lokasi bahan pustaka, susunan bahan pustaka dan jarak antara OPAC dengan rak buku yang jauh menjadi penyebab informasi buku sulit 
ditemukan. Informasi yang terkandung pada buku atau bahan bacaan tidak selamanya mudah diketahui oleh para pengguna. Hal ini disebabkan faktor bahasa, ketebalan buku, dan kondisi buku, sehingga tidak selamanya pengguna yang telah mendapatkan buku dapat memperoleh isi informasi buku. Teknologi menjadikan semua hal menjadi lebih mudah dan praktis, munculnya teknologi Augmented Reality (AR) dan Virtual Reality (VR) yang sekarang berkembang pesat, dapat dimanfaatkan dalam kegiatan di perpustakaan sebagai penunjang layanan perpustakaan dan media belajar bagi para pemustaka terutama pemustaka generasi Z. Penelitian mengenai harapan para pengguna perpustakaan pernah dilakukan oleh Duck (2005), dengan penelitian berjudul "Marketing the Millennials: What They Expect from Their Library Experience" dihasilkan penelitian bahwa harapan para pengguna perpustakaan pada faktor kenyamanan dan penyegaran di perpustakaan serta dukungan teknologi yang digunakan agar dapat mengakses sumber-sumber diluar perpustakaan daripada faktor fasilitas. Perpustakaan diharapkan melayani/ beroperasi lebih lama, mempunyai jaringan nirkabel dan kenyamanan di perpustakaan.Berdasarkan latarbelakang di atas artikel ini akan mengkaji mengenai pemanfaatan teknologi pada perpustakaan untuk pemenuhan kebutuhan informasi bagi pemustaka generasi $Z$.

\section{B. TINJAUAN PUSTAKA}

Augmented Reality (AR) adalah sebuah istilah untuk lingkungan yang menggabungkan dunia nyata dan dunia virtual yang dibuat oleh komputer sehingga batas antara keduanya menjadi sangat tipis. Sistem ini lebih dekat kepada lingkungan nyata, sehingga suatu reality lebih diutamakan pada sistem ini (Brian, 2009). Azuma (1997) mendefinisikan Augmented Reality (AR) sebagai sistem yang memiliki karakteristik menggabungkan lingkungan nyata dan virtual; berjalan secara interaktif dalam waktu nyata; dan terintegrasi dalam tiga dimensi (3D). Suatu sistem Augmented Reality (AR) bertujuan untuk mengambil dunia nyata sebagai dasar dengan menggabungkan beberapa teknologi virtual dan menambahkan data konstektual agar pemahaman manusia sebagai penggunanya menjadi semakin jelas. Data konstektual ini dapat berupa komentar audio, data lokasi, konteks sejarah, atau dalam bentuk lainnya (Rahmat, 2011). Melalui bantuan teknologi Augmented Reality (AR), lingkungan nyata dapat berinteraksi dalam bentuk digital (virtual). Informasi-informasi tentang obyek dan lingkungan disekitar dapat ditambahkan ke dalam sistem Augmented Reality (AR) yang kemudian informasi tersebut ditampilkan diatas 
layer dunia nyata secara real-time seolah-olah informasi tersebut adalah nyata (Fernando, 2013). Fungsi Augmented Reality (AR) untuk meningkatkan persepsi seseorang dari dunia yang ada disekitarnya dan menjadikan sebagian dunia virtual dan nyata sebagai antarmuka yang baru yang mampu menampilkan informasi yang relevan yang sangat membantu dalam bidang pendidikan, pelatihan, perbaikan atau pemeliharaan, manufaktur, militer, permainan, hiburan dan termasuk juga bidang perpustakaan.

Virtual Reality (VR) merupakan konsep yang merujuk pada prinsip, metode dan teknik sebuah sietam yang digunakan dalam perancangan dan pembuatan produk perangkat lunak yang akan digunakan untuk membantu sistem komputasi multimedia dengan kebutuhan perangkat khusus (Lacrama, 2007). Lebih lanjut Sihite (2013) menyatakan bahwa Virtual Reality (VR) atau realitas maya merupakan teknologi yang membuat pengguna dapat berinteraksi dengan suatu lingkungan yang disimulasikan oleh komputer (computer-simulated environment), suatu lingkungan sebenarnya yang ditiru atau benar-benar suatu lingkungan yang hanya ada dalam imaginasi. Diperlukan perangkat pendukung untuk dapat memanfaatkan teknologi VR dan membantu dalam mensimulasikan sesuatu yang sulit dihadirkan pada dunia nyata. Perangkat VR biasanya terdiri dari headset, helm, walker, suit dan sarung tangan. Perangkat ini digunakan dengan melibatkan indera sehingga akan memunculkan sensasi nyata yang lebih tinggi. Teknologi VR mensyaratkan tampilan gambar/grafis/ visual 3D tampak nyata dan sesuai dengan perspektif penggunanya serta mampu mendeteksi semua gerakan yang dilakukan oleh pengguna (Jamil, 2018).

Generasi merupakan suatu konstruksi sosial terdiri dari sekelompok orang yang memiliki kesamaan usia dan pengalaman historis yang sama (Manheim, 1952). Seseorang yang berada dalam lingkup generasi yang sama adalah mereka yang mempunyai kesamaan lahir dalam rentang waktu 20 tahun dan berada pada dimensi sosial yang sama. Lebih lanjut Ryder (1965) menambahkan bahwa generasi merupakan agregat dari sekelompok orang yang mengalami peristiwa yang sama dalam kurun waktu yang sama. Seiring waktu pengertian generasi mengalami perkembangan, menurut Kupperschmidt's (2000) generasi merupakan sekelompok individu dengan kesamaan tahun kelahiran, umur, lokasi dan kejadian-kejadian dalam kelompok tersebut yang berpengaruh terhadap fase pertumbuhan. Beberapa ahli memiliki sedikit perbedaan mengenai penentuan label tiap generasi namun pada prinsipnya memiliki makna yang sama, 
misalnya label generasi Y oleh Martin dan Tulgan (2002) adalah orang-orang yang lahir dikisaran tahun 1978, sedangkan menurut Howe dan Strauss (2000) generasi Y adalah yang lahir di kisaran tahun 1982. Perbadaan terjadi karena beda penggunaan skema dalam pengelompokkan generasi dan dipengaruhi oleh negara yang berbeda. Ada perbedaan pelabelan pada seseorang yang lahir di periode tahun 1990-2000an, penyebutannya antara lain: generasi digital, generasi milenial, Nexters, Generasi Y, Milenial dan Generasi Net. Seiring kemajuan jaman terjadi perubahan populasi penduduk dari masing-masing generasi, dilihat dari angka usia produktif maka jumlah penduduk terbanyak adalah generasi $\mathrm{X}$ dan $\mathrm{Y}$. Namun, disisi lain generasi $\mathrm{Z}$ dan generasi alfa telah muncul sebagai dampak dari kemajuan jaman. Penelitian yang dilakukan oleh Bencsik, Csikos, dan Juhez (2016) menunjukkan masuknya Generasi Z dan generasi alpha dalam kelompok generasi hingga sampai sekarang ini, yang dapat dilihat dalam tabel 1.

Tabel 1. Kelompok Generasi

\begin{tabular}{|c|c|c|}
\hline No & $\begin{array}{c}\text { Tahun } \\
\text { Kelahiran }\end{array}$ & Nama Generasi \\
\hline $\mathbf{1}$ & $1925-1946$ & Generasi Veteran \\
\hline $\mathbf{2}$ & $1946-1960$ & Gen Baby Boomer \\
\hline $\mathbf{3}$ & $1960-1980$ & Generasi X \\
\hline $\mathbf{4}$ & $1980-1995$ & Generasi Y \\
\hline $\mathbf{5}$ & $1995-2010$ & Generasi Z \\
\hline $\mathbf{6}$ & $2010+$ & Generasi Alpha \\
\hline
\end{tabular}

Sumber: Theoritical Review Teori Perbedaan Generasi oleh Yanuar Surya Putra (2016)

Tabel 1 menunjukkan informasi bahwa generasi setelah generasi milenial disebut Generasi Z yang lahir rentang tahun 2001 sampai dengan 2010. Generasi Z ini merupakan peralihan dari Generasi Y atau generasi milenial pada saat teknologi sedang berkembang pesat, megakibatkan pola pikir Generasi $\mathrm{Z}$ cenderung serba instan. Generasi paling muda yang baru memasuki dunia kerja disebut juga iGeneration atau generasi internet. Generasi $\mathrm{Z}$ mampu menerapkan atau mengaplikasikan semua kegiatan dalam satu waktu (multi tasking) seperti: menjalankan sosial media menggunakan ponsel, browsing menggunakan PC, dan mendengarkan musik menggunakan headset. Apapun yang dilakukan kebanyakan berhubungan dengan dunia maya. Sejak kecil generasi ini sudah mengenal teknologi dan akrab dengan gadget canggih yang secara tidak langsung berpengaruh terhadap kepribadian. Kemudian generasi terakhir adalah Generasi Alpha yang lahir pada 2010 hingga sekarang. Generasi ini adalah lanjutan dari generasi $\mathrm{Z}$ yang sudah terlahir pada saat teknologi semakin berkembang pesat. Generasi ini sudah 
mengenal dan sudah berpengalaman dengan teknologi seperti gadget, smartphone dan kecanggihan teknologi lainnya ketika usia mereka yang masih dini.

\section{METODE PENELITIAN}

Metode penelitian yang digunakan adalah studi literatur dengan mencari sumber-sumber referensi yang relevan dengan bahan kajian. Bahan kajian yang digunakan adalah berbagai teoriteori yang melandasi permasalahan yang akan dikaji. Selain itu juga membahas berbagai riset yang sudah dilakukan oleh orang lain yang sejenis dengan topik yang akan dibahas (Suwartono, 2014).

\section{HASIL DAN PEMBAHASAN}

Perkembangan teknologi informasi yang semakin pesat sangat berpengaruh terhadap layanan perpustakaan. Kepuasan pengguna menjadi tujuan utama dari layanan suatu perpustakaan, semakin lengkap informasi yang diberikan maka semakin terpenuhi kebutuhan informasi pemustaka. Pemanfaatan teknologi sebagai upaya dalam meningkatkan kualitas layanan perpustakaan harus dilakukan seiring dengan perkembangan teknologi terkini. Salah satu teknologi yang lahir pada jaman generasi Z adalah Augmented Reality dan virtual reality, oleh sebab itu perpustakaan harus dapat memanfaatkan teknologi tersebut guna memenuhi kebutuhan informasi dan mendukung kegiatan-kegiatan di perpustakaan. Menurut Massis (2015) pada artikel berjudul "Using virtual and Augmented Reality in the library" terdapat beberapa contoh penerapan dari teknologi Augmented Reality dan Virtual Reality pada perpustakaan, yaitu Aurasma, EON Realitas, dan Layar.

Aurasma merupakan aplikasi gratis yang dapat diunduh dari perangkat iOS atau Android. Cara penggunaan aplikasi ini dengan memfokuskan camera smartphone pada objek yang dituju misalnya koleksi buku perpustakaan. Aplikasi ini akan memberikan informasi tambahan terhadap sebuah objek didalam buku. Penggunaan Aurasma dapat menarik pengunjung dan menghidupkan suasana dalam sebuah pameran perpustakaan, galeri, seni. Selain itu serangkaian poster, foto disebuah majalah dapat ditambahkan realitas tambahan seperti kombinasi grafik, animasi, video dan narasi sehingga bisa memperluas minat pada topik tertentu yang dipicu oleh aplikasi Aurasma. 
Eon Realitas merupakan sebuah pengaplikasian dan pengembangan dari konsep Virtual Reality yang ditujukan untuk dunia pendidikan, industri dan olahraga. Konten-konten pembelajaran EON realitas ini dapat membantu siswa dalam belajar secara mandiri. EON ini bisa menghadirkan pembelajaran yang interaktif dan menarik karena siswa akan melihat secara nyata sebuah proses pembelajaran melalui VR. VR interaktif melalui pengalaman tiga dimensi dapat ditemukan di EON Reality, di mana mobile VR (EON Mobile) dapat dipilih atau dikembangkan juga untuk perangkat pintar iOS atau Android oleh perpustakaan, pendidik dan siswa. Saat ini teknologi ini sudah digunakan digunakan di Carnegie Mellon University (USA), Imperial College (Inggris), Nanyang Universitas Teknologi (Singapura) dan banyak lembaga pendidikan lainnya, di mana, dalam lingkungan belajar terpadu, kombinasi pembelajaran di kelas dan online.

Layar merupakan aplikasi Augmented Reality yang juga tersedia untuk $i O S$, Android dan perangkat Blackberry. Mirip dengan konsep yang ditawarkan oleh Aurasma, aplikasi ini memungkinkan pembuat konten untuk menambahkan multimedia dari semua jenis untuk membawa gambar statis ke kehidupan dan meningkatkan pengalaman pemakainya. Layar dapat meningkatkan selebaran kartu pos, kemasan atau barang lainnya kedalam konten interaktif, termasuk pesan, video, tautan web, rangkaian slide foto, klip musik dan lain sebagainya.

Implementasi Teknologi Augmented Reality (AR) pada Perpustakaan Generasi Z, yaitu, pertama sebagai brosur opac interaktif. Salah satu informasi yang sering diberikan oleh para pustakawan adalah tata cara penggunaan OPAC (Katalog Online) baik penyampaian secara langsung maupun melalui media brosur. Namun, penggunaan brosur dalam promosi perpustakaan pada era sekarang sudah mulai ditinggalkan sehingga sudah tidak relevan lagi, untuk mengatasi permasalahan tersebut maka perlu pemanfaatan teknologi AR sebagai sarana simulasi OPAC dengan tetap menggunakan brosur yang sudah ada. Melalui teknologi AR, tampilan brosur menjadi lebih interaktif karena ketika dilihat pada layar smartphone maka otomatis akan langsung memunculkan berbagai informasi mengenai isi brosur yang berbentuk virtual pada layar smartphone serta terdapat panduan berupa video bagaimana cara penggunaan OPAC. Hal ini menjadikan tugas pustakawan semakin mudah dalam memberikan layanan user education dan literasi informasi pada pemustaka (Raharjo, 2014).

Implementasi Teknologi Augmented Reality (AR) pada Perpustakaan Generasi Z yang kedua adalah sebagai display koleksi perpustakaan. Koleksi perpustakaan berupa terbitan 
tercetak seperti buku, jurnal ilmiah, majalah, tabloid, koran, buku fiksi dan nonfiksi, peta, foto, video dan lain-lain disusun sesuai dengan media yang digunakan. Pada era teknologi sekarang ini pemanfaatan koleksi perpustakaan dalam bentuk tercetak mulai ditinggalkan dan para pemustaka generasi $\mathrm{Z}$ lebih memilih ke bentuk media digital atau elektronik. Pemanfaatan teknologi AR pada koleksi perpustakaan dapat menarik para pemustaka generasi $\mathrm{Z}$ karena secara tampilan akan berubah kedalam bentuk virtual dan lebih sesuai dengan perkembangan teklonogi sekarang ini.

Implementasi Teknologi Augmented Reality (AR) pada Perpustakaan Generasi Z yang ketiga adalah sebagai penelusuran koleksi perpustakaan di rak. Karakteristik pemustaka dalam melakukan penelusuran dan pencarian buku atau koleksi di perpustakaan berbeda-beda, ada yang langsung menuju OPAC ada yang langsung ke rak buku dan ada yang langsung bertanya ke pustakawan. Hal ini disebabkan karena banyaknya para pemustaka yang tidak tahu cara penggunaan OPAC dalam mencari bahan bacaan yang diperlukan atau karena para pemustaka memang lebih suka langsung mencari tanpa melihat petunjunjuk dalam OPAC. Perilaku pemustaka tersebut menjadikan layanan perpustakaan tidak efektif dan efisien karena membutuhkan waktu yang lebih lama dalam mencari dan menemukan buku yang dibutuhkan. Pemanfaatan teknologi AR merupakan jawaban dari permasalahan tersebut, karena melalui penggunaan smartphone atau tablet yang dimiliki oleh para pemustaka bisa langsung memindai atau scanning pada deretan buku yang ada pada rak di perpustakaan. Teknologi AR akan memunculkan informasi isi dari masing-masing rak serta menampilkan informasi dari masingmasing buku dari mulai judul pengarang, penerbit, edisi, tahun, daftar isi dan tanggal buku. Penggunaan AR memberikan manfaat kepada pengguna karena terhidar dari kesalahan mengambil buku, dan dapat dilakukan dengan cepat dan tepat sehingga lebih efisien. (Raharjo, 2014).

Implementasi Teknologi Augmented Reality (AR) pada Perpustakaan Generasi Z yang keempat adalah sebagai media pembelajaran interaktif bagi pemustaka. Teknologi AR merupakan aplikasi penggabungan dunia nyata dengan dunia maya dalam bentuk dua dimensi maupun tiga dimensi yang diproyeksikan dalam sebuah lingkungan nyata dalam waktu yang bersamaan (Mustaqim, 2017). Penggunaan AR sebagai media pembelajaran diharapkan dapat menarik para siswa generasi $\mathrm{Z}$ untuk menggunakan bahan pustaka sebagai media belajar. Melaui teknologi AR, perpustakaan dapat membantu membuat media pembelajaran yang lebih 
menyenangkan, interaktif, dan mudah digunakan. AR juga dapat digunakan untuk menggantikan modul pembelajaran yang belum ada di sekolah dan para pemustaka (siswa) tetap dapat melihat dan menggunakan modul yang sudah ada seperti modul aslinya, namun dalam bentuk virtual atau maya.

Adapun implementasi teknologi Virtual Reality (VR) pada perpustakaan generasi z yang pertama, adalah sebagai sarana yang digunakan untuk mendukung layanan perpustakaan. Beberapa contoh kegiatan dalam perpustakaan yang memanfaatkan teknologi VR menurut Jamil (2018), yaitu, pertama sebagai wisata perpustakaan. Wisata perpustakaan merupakan kegiatan dengan bentuk wisata atau tur virtual perpustakaan yang bisa dilakukan untuk menunjukkan cara berkeliling perpustakaan, dan menemukan koleksi perpustakaan di rak buku dengan lebih mudah dan praktis. Manfaat wisata pepustakaan virtual untuk memudahkan akses ke semua tempat dan ruangan apabila secara fisik gedung perpustakaan sangat luas. Konsep ini sangat cocok bagi pemustaka difabel, pemustaka berusia lanjut dan pemustaka dengan keterbatasan fisik lain dengan mobilitas rendah.

Implementasi teknologi Virtual Reality (VR) yang kedua adalah dapat digunakan pada layanan perpustakaan. Teknologi VR pada layanan perpustakaan terutama layanan referensi dapat berfungsi sebagai directional reference bagi pemustaka. Menurut Meredith (2014) idealnya dapat melakukan empat hal berikut ini yaitu: 1) memberikan arahan lokasi tiga dimensi tentang perpustakaan dan gedung perpustakaan; 2) memberikan informasi visual yang mengarahkan kepada koleksi yang diperlukan; memungkinkan pencarian menggunakan suara (execute a voice-search); 4) menyediakan pengguna pilihan untuk mengeksplorasi konten digital yang bersifat virtual di dalam lingkungan yang nyata.

Implementasi teknologi Virtual Reality (VR) yang ketiga adalah sebagai betuk literasi informasi. Pemanfaatan VR dalam proses literasi informasi akan banyak berhubungan dengan pengayaan materi literasi dalam formatyang bisa diakses dengan peralatan VR. Materi ini dapat berisi segala informasi dan pengetahuan yang sudah biasa ada dalam modul literasi informasi yang diperoleh dengan memproduksi sendiri atau mengeksplore materi yang sudah banyak terdapat secara online untuk memudahkan para generasi Z memanfaatkan bahan-bahan literasi yang ada. 
Implementasi teknologi Virtual Reality (VR) yang ketiga adalah sebagai katalog online. Sistem VR secara sederhana dapat diterapkan dalam sistem katalog online yang akan memberikan kemudahan pada pemustaka generasi Z. Pemustaka akan dituntun secara virtual dalam tampilan 3D menuju rak koleksi untuk menemukan koleksi yang dicari sebelum pemustaka tersebut benar-benar menuju ke rak koleksi secara fisik.

\section{E. KESIMPULAN DAN SARAN}

Perpustakaan di era sekarang ini harus mampu menyesuaikan dengan kebutuhan dan keinginan para generasi Z. Teknologi yang berkembang telah merubah perilaku dan persepsi para pemustaka bahwa segala sesuatu harus berbentu elektronik dan digital. Oleh karena itu, hendaknya saat ini perpustakaan harus mulai dapat memanfaatkan teknologi augmented reality dan virtual reality sebagai upaya promosi agar perpustakaan dapat menarik perhatian para generasi $\mathrm{Z}$ untuk mau memanfaatkan perpustakaan sebagai tempat untuk memenuhi kebutuhan informasi dan pengetahuan yang diperlukan.

\section{DAFTAR PUSTAKA}

Azuma, Ronald T. 1997. A Survey of Augmented Reality. Presence: Teleoperators and Virtual Environments 6.

Bencsik, A., Csikos, G., \& Juhaz, T. (2016). Y and Z Generations at Workplaces. Journal of Competitiveness, 8(3), 90-106. https://doi.org/10.7441/joc.2016.03.06

Duck, Patricia M and Randi Koeske. (2005). Marketing the Millennials: What They Expect from Their Library Experience. (ACRL) Association of Collage and Research Libraries. Twelfth National Conference. April 5-7 2005. Page 112-120

Fernando, Mario. 2013. Skripsi: Membuat Aplikasi Augmented Reality Menggunakan Vuforia SDK dan Unity. Manado: Universitas Klabat Manado.

Howe, N., \& Strauss, W. (2000). Millennials rising: The next great generation. New York: Vintage.

Kupperschmidt, B. R.; 2000; Multigeneration Employees: Strategies for Effective Management; The Health Care Manager, 19(1), 65.

Mannheim, K. (1952). The Problem of Generations. Essays on the Sociology of Knowledge, 24(19), 276-322-24.

Martin, C. A. and Tulgan, B. (2002). Managing the Generational Mix. Amherst, MA: HRD Press.

Massis, Bruce. (2015). Using virtual and Augmented Reality in the library. New Library World. Vol. 116 No. 11/12, 2015. pp 796-799. Emerald Group Publishing Limited. ISSN 0307-4803 DOI 10.1108/NLW-08-20150054

Meredith, T.R. (2014). Using Augmented Reality Tools to Enhance Children,s Library Services. Technology, Knowing and Learning. Volume 20, Issue 1, pp 71-77.

Mustaqim, Ilmawan dan Nanang Kurniawan. (2017). Pengembangan Media Pembelajaran Berbasis Augmented Reality. Jurnal Edukasi Elektro, Vol. 1, No. 1, Mei 2017 e-ISSN : 2548-8260. Hal. 36-48 
Putra, Yanuar Surya. (2016). Theoritica Review: Teori Perbedaan Generasi. Among Makarti Vol.9 No.18, Desember 2016. Hal. 123-134

Raharjo, Priyo. (2014). Penerapan Teknologi Augmented Reality (AR) di Perpustakaan. Knowledge and Information Center. Diakses tanggal 15 Mei 2019. Sumber: https://priyo75.wordpress.com/2014/12/19/penerapanteknologi-augmented-reality-ar-di-perpustakaan/

Rahmat, Berki. 2011. Analisis dan Perancangan Sistem Pengenalan Bangun Ruang Menggunakan Augmented Reality. Medan: Universitas Sumatera Utara.

Ryder, N. B. (1965). The Cohort as a Concept in the Study of Social Change. American Sociological Review, 30(6), 843-861. https://doi.org/10.2307/2090964

Suwartono. (2014). Dasar-Dasar Metodologi Penelitian. Yogyakarta: Andi Offset.

Yudhastara, Brian. 2012. Teknologi Augmented Reality Untuk Buku Pembelajaran Hewan pada Anak Usia Dini Secara Virtual. Yogyakarta: STIMIK AMIKOM. 
